\title{
Role of the ventral tegmental area in methamphetamine extinction: AMPA receptor-mediated neuroplasticity
}

\author{
Han-Ting Chen ${ }^{1}$ and Jin-Chung Chen ${ }^{1,2,3}$ \\ ${ }^{1}$ Department of Physiology and Pharmacology, Institute of Biomedical Sciences, School of Medicine, Chang-Gung University, \\ Tao-Yuan 333, Taiwan; ${ }^{2}$ Healthy Ageing Research Center, Chang-Gung University, Tao-Yuan 333, Taiwan; ${ }^{3}$ Neuroscience Research \\ Center, Chang-Gung Memorial Hospital, Tao-Yuan 333, Taiwan
}

\begin{abstract}
The molecular mechanisms underlying drug extinction remain largely unknown, although a role for medial prefrontal cortex (mPFC) glutamate neurons has been suggested. Considering that the mPFC sends glutamate efferents to the ventral tegmental area (VTA), we tested whether the VTA is involved in methamphetamine (METH) extinction via conditioned place preference (CPP). Among various METH-CPP stages, we found that the amount of phospho-GluR1/Ser845 increased in the VTA at behavioral extinction, but not the acquisition or withdrawal stage. Via surface biotinylation, we found that levels of membrane GluR1 were significantly increased during METH-CPP extinction, while no change was observed at the acquisition stage. Specifically, the number of dendritic spines in the VTA was increased at behavioral extinction, but not during acquisition. To validate the role of the $\mathrm{mPFC}$ in METH-CPP extinction, we lesioned the mPFC. Ibotenic acid lesioning of the mPFC did not affect METH-CPP acquisition, however, it abolished the extinction stage and reversed the enhanced phospho-GluR1/Ser845 levels as well as increases in VTA dendritic spines during METH-CPP extinction. Overall, this study demonstrates that the mPFC plays a critical role in METH-CPP extinction and identifies the VTA as an alternative target in mediating the extinction of drug conditioning.
\end{abstract}

[Supplemental material is available for this article.]

Drug addiction is described as a phenomenon of compulsive drug use, which is accompanied by a high rate of relapse even after prolonged drug abstinence while applicable treatment regimens remain relatively ineffective (Kreek et al. 2002). Since substance abuse is readily reinstated by priming stimuli (e.g., conditioned cues, stressors, or drug per se), elimination of cognitive salience for drug-paired inducers is considered to be an effective strategy to combat drug addiction (Aguilar et al. 2009). One such intervention technique involves strengthening extinction sessions, wherein a subject engages in repetitive exposures to nonreinforced cues. This occurs following abstinence from drug reinforcement and typically results in a decline of the intensity of drug-seeking behavior (Conklin and Tiffany 2002). In laboratory animals, extinction training has been successfully used to reduce the cue-associated behaviors after reexposure to the original drugpaired context. In particular, delineating the neural processes that occur during extinction of drug-cue pairing would be an important advance in the effort to renovate drug extinction programs and more effectively prevent drug relapse.

Previous studies examining the neural circuitry of drug extinction have revealed that the amygdala (Akirav and Maroun 2007; Yap and Miczek 2008), hippocampus (Kelamangalath et al. 2007; Cleva et al. 2010), nucleus accumbens (NAc) (Knackstedt et al. 2010; Millan and McNally 2012), and medial prefrontal cortex (mPFC) (Willcocks and McNally 2013; Yetnikoff et al. 2014) are cardinal brain structures that participate in drug extinction and reinstatement (Quirk and Mueller 2008). Of interest, evidence mostly generated from heroin- or cocaine-SA (self-administration) paradigms shows that the prelimbic and infralimbic cortex appear to display functionally distinct roles in modulating drug extinction and reinstatement (Peters et al. 2009). For instance, infusion

Corresponding author: jinchen@mail.cgu.edu.tw

Article is online at http://www.learnmem.org/cgi/doi/10.1101/Im.037721.114. of GABA agonists into prelimbic cortex did not affect the expression of extinction, but attenuates context-induced alcohol reinstatement (Willcocks and McNally 2013). Inactivation of the infralimbic cortex with lidocaine had no effect on MDMA-extinction, while prelimbic cortex inactivation completely blocked MDMA reinstatement (Ball and Slane 2012). On the other hand, c-Fos expression was noted in prelimbic cortex during cocaine extinction training, and also increased in the infralimbic cortex of cocaine-cue extinguished rats (Nic Dhonnchadha et al. 2013). Stimulation of glutamate activity in the infralimbic cortex was found to attenuate cocaine reinstatement in extinguished animals, requiring a neural connection with NAc (Peters et al. 2008). Those evidences implicate the precise role of prelimbic and infralimbic of the mPFC in manipulating drug extinction and reinstatement remained inconclusive.

In contrast to the substantial volume of reports exploring the behavioral aspects of drug extinction, there are relatively few which provide evidence of neurochemical underpinnings. Based on the current view that extinction represents a new form of learning, involvement of glutamate-mediated excitatory signaling would be a necessity (Zavala et al. 2007; Hsu and Packard 2008; Peters et al. 2008; Ghasemzadeh et al. 2009b). In support of this hypothesis, it was found that systemic administration of a competitive NMDA receptor antagonist during extinction training would no longer block cocaine reinstatement induced by cocaine priming (Kelamangalath et al. 2007). Furthermore, several neuroadaptive alterations were identified in glutamate receptor

(C) 2015 Chen and Chen This article is distributed exclusively by Cold Spring Harbor Laboratory Press for the first 12 months after the full-issue publication date (see http://learnmem.cshlp.org/site/misc/terms.xhtml). After 12 months, it is available under a Creative Commons License (Attribution-NonCommercial 4.0 International), as described at http://creativecommons.org/ licenses/by-nc/4.0/. 
containing neurons. First, the amount of NMDA receptor subunit NR1 protein and mRNA was increased in the PFC during initial extinction training following cocaine-SA (Crespo et al. 2002). In a similar cocaine-SA schedule, protein levels of NR1 as well as GluR1 and GluR2/3 subunits of AMPA ( $\alpha$-amino-3-hydroxy5-methyl-4-isoxazolepropionic acid) receptor in both NAc and dorsal striatum were all increased after extinction training (Ghasemzadeh et al. 2009a). Importantly, an increase in phosphorylation of GluR1/Ser845 has been observed in the hippocampus during morphine-CPP extinction, suggesting an enduring neural plasticity change that may provide the neurochemical basis of long-term potentiation (LTP) (Billa et al. 2009). Phosphorylation at Ser845 would increase the insertion rate of AMPA receptors in membrane, while phosphorylation of AMPA receptor at Ser831 would increase the conductance of GluR1 and/or GluR2 (Lee and Kirkwood 2011; Jenkins and Traynelis 2012). In agreement with these studies, extinction training reversed the conditioning-dependent GluR1 surface expression in the amygdala, in parallel with an inhibition of fear conditioning (Mao et al. 2006). These findings suggest that it may be practical to target glutamate NMDA and AMPA receptor-dependent cellular events to modulate the outcome of extinction.

Neuroimaging studies in drug addicts indicate that drugassociated cues evoke neural activation in both the mesolimbic and mesocortical dopamine (DA) system. This is the same neural circuitry that is known to mediate drug reward (Tzschentke 2001). In view of previous literature, it is quite surprising that there is no report examining the role of VTA in drug extinction or reinstatement. Dopaminergic neurons in the VTA are known to project to the MPFC via the mesocortical DA projection that plays a key role in determining the predictive value of reward-paired stimuli (Tzschentke 2001). Reciprocally, the mPFC also sends a glutamate projection to the VTA innervating both DA and GABA neurons with unclear functionality (Carr and Sesack 2000). The aim of this study is to first, characterize the biochemical and morphological features of the VTA during acquisition and extinction of METH-CPP and then, explore the impact of the mPFC on METH-CPP extinction. We find that (1) biochemical (AMPA receptor phosphorylation and surface expression) and morphological (dendritic spine) changes occurred in the VTA across pretest, acquisition, and extinction stages of METH-CPP; (2) lesioning the mPFC significantly blocked the extinction, but not the acquisition, of METH-CPP along with concomitant biochemical/morphological alterations in the VTA.

\section{Results}

We first established a METH-CPP acquisition and extinction model in mice and compared with two CPP control groups, i.e., saline treatment and withdrawal control. Results showed that there were main effects on CPP stages $\left(F_{(2,28)}=28.12, P<0.0001\right)$ and CPP stages $x$ treatment interaction $\left(F_{(4,28)}=7.64, P=0.0003\right)$ (Fig. 1). Among treatment groups, mice of control group that paired with saline in both compartments displayed no place preference. However, mice paired with METH in designated compartment acquired METH-CPP and returned to approximately pretest preference following subsequent $8 \mathrm{~d}$ extinction training (Fig. 1; $\left.F_{(2,12)}=13.16, \quad P<0.001\right)$; nevertheless, mice of withdrawal group maintained their place preference in previous METH-paired compartment though they went through an equivalent withdrawal session in a novel mouse cage (Fig. $1, F_{(2,21)}=16.97, P>$ 0.05) indicating METH-CPP extinction is cue-dependent.

Previously, it was found that mPFC glutamate projections to subcortical brain regions, including the midbrain VTA, represents a major neural network in determining the outcome of extinction behavior (Kalivas and Volkow 2011; Lüscher and Malenka 2011). To validate the significance of glutamate input on VTA neurons, each experimental group was subjected to analyze the expression of AMPA receptor subunits in the VTA, at the level of both total protein and specific phosphorylated forms at GluR1/ Ser831 and Ser845 because these GluR1 phosphorylation seems to serve as an indicator for altered neuroplasticity (Derkach et al. 2007; Kessels and Malinow 2009; Henley and Wilkinson 2013). The results show that although RNA level of total GluR1 increased during acquisition (Fig. $2 \mathrm{~A} ; F_{(2,7)}=0.40, P<0.05$ ), total GluR1 protein and phosphorylation levels of GluR1/Ser831 did not change across the METH-CPP acquisition, withdrawal, or extinction stage (Fig. 2B; $F_{(3,16)}=1.22, P>$ 0.05 ; Fig. 2C, $\left.F_{(3,32)}=1.39, P>0.05\right)$. On the other hand, levels of phosphorylated GluR1/Ser845 increased at the extinction stage (Fig. 2D; $F_{(3,28)}=7.75$, $P<0.001)$. To further substantiate the role of GluR1/Ser845 on METH-CPP, we then tested if stress (physical restraint)induced METH-CPP reinstatement involves change of GluR1/Ser845 phosphorylation in the VTA. The results showed that none of total GluR1 and GluR1/Ser831 and GluR1/Ser845 phosphorylation exhibited amount difference between METH-CPP extinction and stress-induced reinstatement groups, though there was a trend of decrease in GluR1/Ser845 phosphorylation during reinstatement (Supplemental Fig. S2). In order to examine a downstream signal regulator, we analyzed the activity of ERK1/2 in VTA. ERK1/2 is known to play an important role in acquisition of drug CPP (Girault et al. 2007; Xu et al. 2012; Ma et al. 2014). The results show that phospho-ERK2 decreased in the VTA during METH-CPP acquisition and
Figure 1. Time (mean \pm SEM) that animals spent in drug-paired compartment (or nonpreferred compartment for saline control) before (pretest) METH- or saline-CPP training, after METH-CPP training (acquisition), and after extinction or withdrawal training. Saline control (S/S-S/S) group: mice treated with saline throughout all the CPP acquisition or extinction training. Withdrawal (S/M-S/cage) group: mice acquired METH-CPP then treated with saline and exposed to a new mouse cage for $30 \mathrm{~min}$. Extinction (S/M-S/S) group: mice went through METH-CPP acquisition and extinction training. $\left({ }^{*}\right)$ $P<0.05$, (**) $P<0.01$ compared with corresponding pretest CPP score; (\#) $P<0.05$ compared with corresponding acquisition CPP score; $(+) P<0.05$ compared with extinction of withdrawal group. ( $N=5-7$ per group). 
A

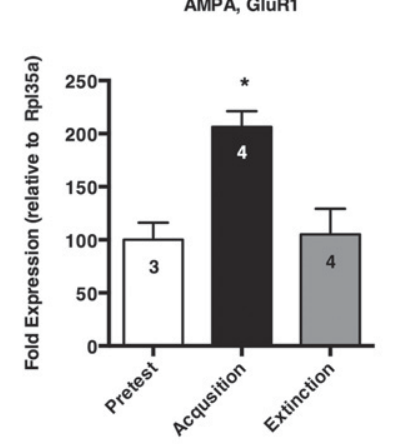

B

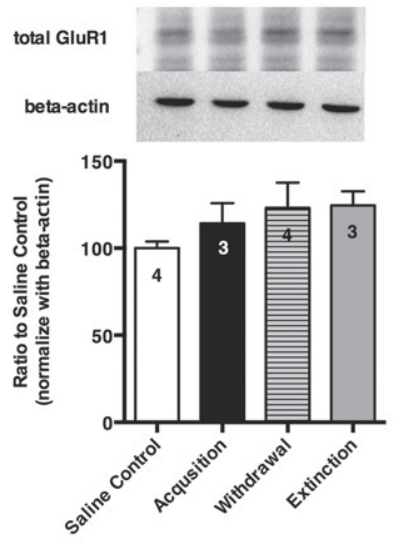

C

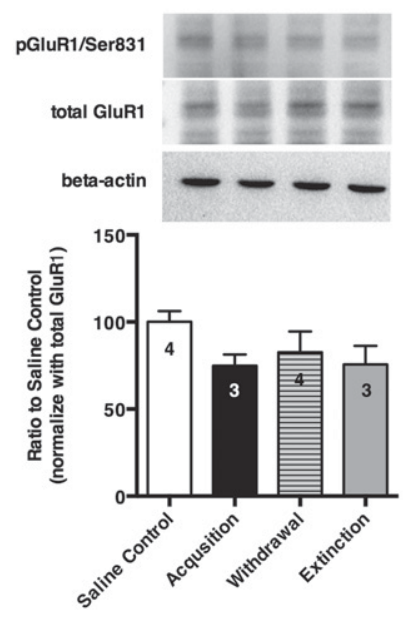

D

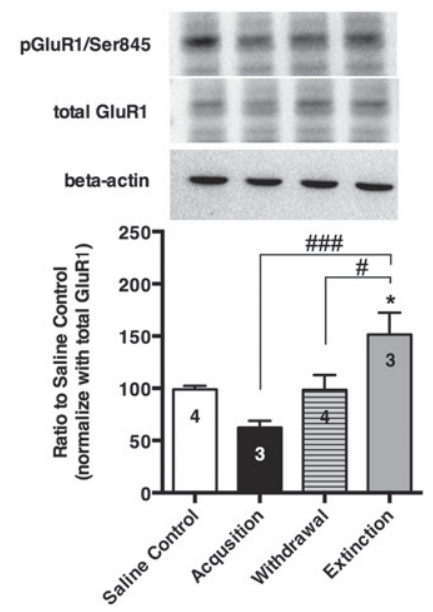

$\mathbf{E}$

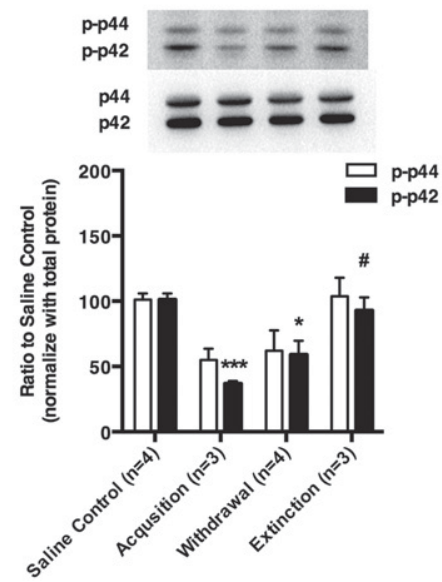

Figure 2. Quantification of GluR1 mRNA $(A)$ and protein levels of total AMPA receptor subunit GluR1 (B), phosphorylated GluR1/Ser831(C), phosphorylated GluR1/Ser845, $(D)$ and phosphorylated ERK1/2 (p-p44/p-p42) (E) in the VTA of saline control, acquisition, withdrawal, and extinction stages of METH-CPP. Representative Western blots are shown. Bar graphs show qPCR or densitometric quantification with pretest score or saline control set as $100 \%$. Phosphorylated and total proteins were both normalized to $\beta$-actin before phospho/total rationed to each other. Amount of total GluR1 was normalized to $\beta$-actin. $(*) P<0.05,\left({ }^{* *}\right) P<0.001$ compared with pretest group or corresponding saline controls; $(\#) P<0.05$, (\#\#\#) $P<0.001$ compared with corresponding withdrawal or acquisition group. Bilateral VTA from $\sim 3-4$ mice were pooled in each experiment. The experiments were repeated at least three times.

withdrawal as compared with saline controls, but returned to control level during extinction (Fig. 2E; p-p42, $F_{(3,12)}=14.96, P<$ 0.001). As shown in Figure $2 \mathrm{E}$, phospho-ERK1 displayed a similar pattern as phospho-ERK2, however did not reach statistical significance $\left(F_{(3,12)}=4.84, P>0.05\right)$.

LTP-related GluR1/Ser831 and Ser845 phosphorylation enhances GluR1 translocation to cell membrane and is coupled to alterations in structural morphology of dendritic spines (Kessels and Malinow 2009; Fortin et al. 2010; Jenkins and Traynelis 2012). To assess changes in membrane GluR1 and dendritic morphology during different stages of METH-CPP, we first performed a surface biotinylation assay on GluR1 in a VTA synaptosomal preparation. The amount of membrane GluR1 was found to be increased significantly during METH-CPP extinction, but not acquisition, as compared with pretest controls (Fig. 3A, $F_{(2,6)}=$ $15.45, P<0.01)$. Next, via Golgi stain, we monitored and calculated the numbers of dendritic spines in the VTA across different METH-CPP stages. As illustratred in Figure 3B-F, similar to the results of GluR1 surface expression, numbers of dendritic spine increased significantly in the VTA during METH-CPP extinction, but remained unchanged at acquisition and withdrawal stages when compared with pretest controls (Fig. $3 \mathrm{~B}, F_{(3,22)}=5.76$, $P<0.01)$. Stress-induced METH-CPP reinstatement, on the other hand, could not modify the neuroplasticity in the VTA as numbers of dendritic spine remained similar as drug extinction group (Supplemental Fig. S2).

To investigate the impact of the MPFC on METH-CPP acquisition and extinction, we lesioned the MPFC with ibotenic acid ( $5 \mu \mathrm{g}$ in each bilateral) $2 \mathrm{~d}$ prior to the first METH-CPP test. Figure $4 \mathrm{~A}$ illustrates the location of drug delivery at the mPFC. Location of the injection was assessed after $18 \mathrm{~d}$ of METH-CPP acquisition and extinction training. The lesion-caused cell damage and atrophy remained obvious when compared with sham group (data not shown). The extent of METH-CPP acquisition in both sham (Fig. $4 \mathrm{~B}, F_{(2,39)}=10.71, P<0.001$ ) and lesioned group (Fig. $\left.4 \mathrm{~B}, F_{(2,35)}=10.72, P<0.001\right)$ was similar when compared with pretest control. However, the lesion significantly affected METH-CPP extinction since mPFC lesioned animals displayed a 
A
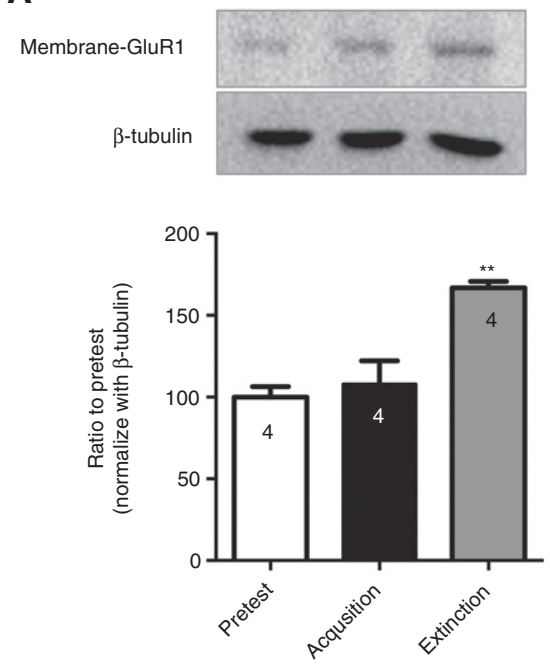

$\mathbf{B}$

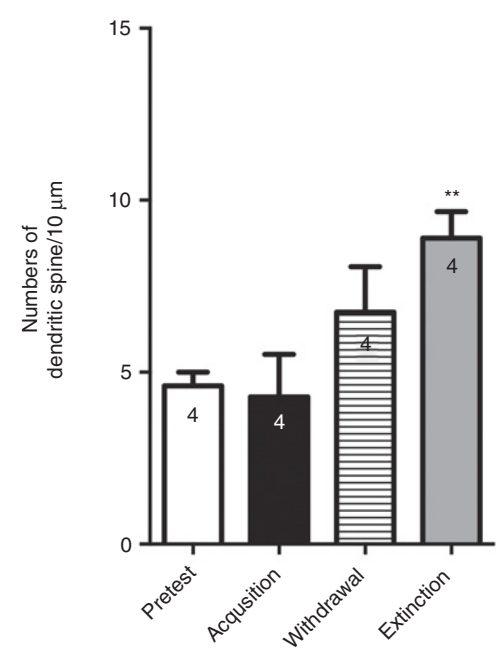

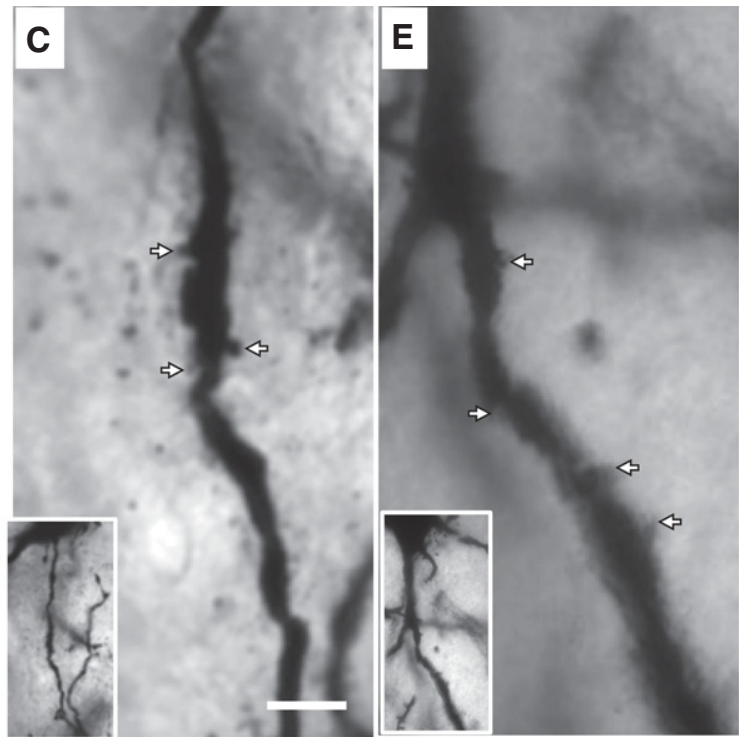

D
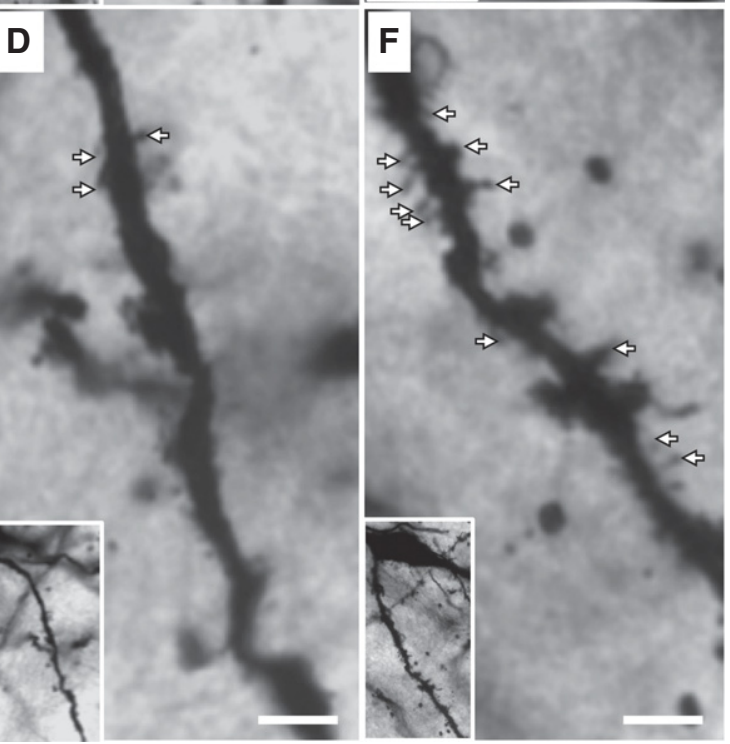

Figure 3. (A) Biotinylation of GluR1 subunit from a VTA synpatosomal preparation. Representative Western blots are shown. Bar graphs show densitometric quantification. ( $C-F)$ Golgi stain to illustrate the structural modifications in the VTA during the period of pretest $(C)$, acquisition $(D)$, withdrawal $(E)$, and extinction $(F)$ of METH-CPP with bar graphs $(B)$ showing quantification of dendritic spines. Scale in each panel is $5 \mu \mathrm{m}$. Arrows indicate the dendritic spines. $\left({ }^{*}\right) P<0.01$ compared with corresponding pretest controls. Bilateral VTA from $\sim 2-3$ mice were pooled in each Western blot experiment and experiments were repeated four times. For Golgi stains, sections from 3 to 4 mice per group were calculated.

similar degree of METH-CPP as preference recorded in the acquisition stage. This result indicates that $\mathrm{MPFC}$ lesioning specifically blocks METH-CPP extinction.

To further validate the role of the MPFC in METH-CPP extinction, we analyzed the protein levels of GluR1 and its phosphorylation status in the VTA of both sham and lesioned animals. As shown in Figure 5, mPFC lesioning significantly reduced the total amount of GluR1 in both groups of animals (Fig. 5A, $F_{(2,6)}=$ 23.10, $P<0.05)$. In contrast, lesioning significantly reduced the levels of GluR1/Ser845 phosphorylation after METH-CPP extinction, but not sham control, as compared with extinction group (Fig. 5B, $\left.F_{(2,6)}=56.20, P<0.001\right)$. Concomittently, mPFC lesioning resulted in a similar effect on the structural morphology of the VTA, since the number of dendritic spines was reduced in the mPFC lesioned group as compared with sham extinction group (Fig. 5E, $\left.F_{(5,5)}=9.42, P<0.05\right)$.

\section{Discussion}

In the current study, we demonstrate that cue-associated METH extinction could be effectively suppressed by mPFC lesioning prior to METH-CPP training, while the lesion did not affect the acquisition of METH-CPP. This result is consistent with a general view that the mPFC participates in extinction of aversive or appetitive conditioned response (Guedea et al. 2011; Groblewski et al. 2012). Importantly, the current findings also lead us to conclude that the VTA is an additional brain region involved in the neural process of drug extinction. In support of this conclusion, the amount of membrane GluR1 and Ser845 phosphorylation in the VTA increased after METH-CPP extinction training while levels were decreased after mPFC lesion. The change in membrane GluR1 is expected to functionally link with neuroplasticity since number of dendritic spines was also found increased 
A

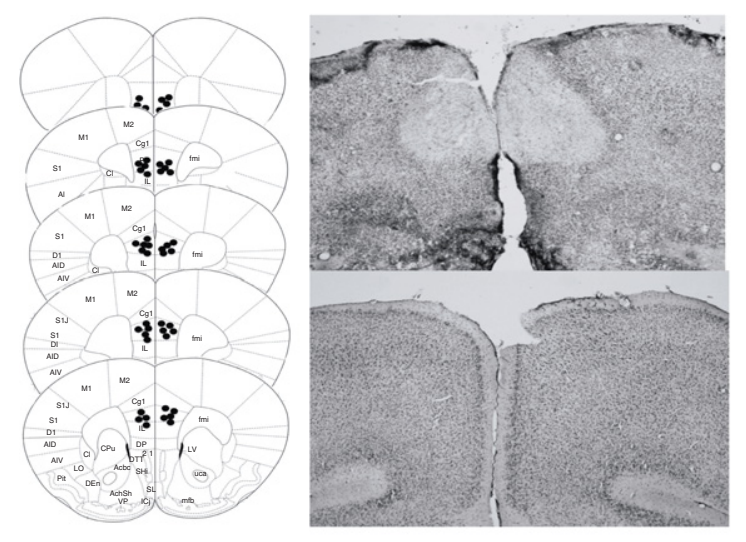

B

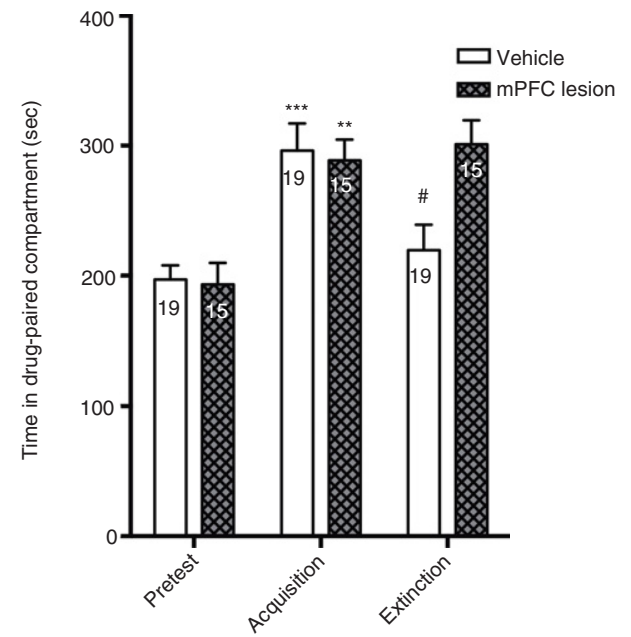

Figure 4. Effect of $\mathrm{mPFC}$ lesioning on METH-CPP acquisition and extinction. $(A)$ Brain sections from animals receiving saline (left) or ibotenic acid lesion (right) aiming at the $\mathrm{mPFC}$, as verified on Nissl-stained sections. (B) Bar graphs indicate time (mean \pm SEM) spent in METH-paired compartment before training, after acquisition, or after extinction training. $\left({ }^{* *}\right) P<0.01$, $\left({ }^{* *}\right) P<0.001$ compared with corresponding pretest controls; (\#) $P<0.001$ compared with corresponding acquisition groups. $N=15-19$ per group.

in the VTA at METH-CPP extinction, but remained at pretest control levels in mPFC lesioned animals. We speculate that VTA GABAergic neurons might be the target for receiving mPFC excitatory glutamate inputs during extinction training. These neurons then send an inhibitory signal to suppress nearby mesolimbic dopamine activity, thereby dampening the recurrence of METH-CPP.

Drug addiction is a chronic relapsing disorder with characteristic repetitive drug taking, or craving during abstinent periods. To extinguish craving, dissociation with drug-associated cues has been attempted. Strategies that have been successfully used in animal experiments include cue exposure therapy, wherein subjects are exposed to drug-associated environments in the absence of drug pairing (Haaker et al. 2013). Cue exposure therapy has been used quite successfully in treatment of fear conditioning, including reduced anxiety in PTSD patients or electrically shocked rodents (Grillon 2008; Indovina et al. 2011). However, a low success rate was reported using the strategy for extinction of cue-dependent drug taking in drug addicts (Conklin and Tiffany 2002; Crombag and Shaham 2002), probably due to the highly context-dependent nature of drug extinction (Peters et al. 2009; Taylor et al. 2009). Through a wealth of fear conditioning animal studies, it was recognized that extinction training encodes a form of new learning that requires a course of acquisition, consolidation, and retrieval (Quirk and Mueller 2008). Hence, it is reasonable to find that extinction training changes overall amount or phosphorylation levels of NMDA and/or AMPA receptors in designated brain areas (Spaethling et al. 2012). Extinction of cocaine self-administration induced an up-regulation of GluR1 and GluR2/3 in the NAc-shell that linked to a reduction of subsequent cocaine-seeking behavior (Sutton et al. 2003). These changes provide a valuable marker, which has been used to trace the neural framework underlying extinction learning. For instance, enhanced GluR1/Ser845 phosphorylation was found in both NAc and ventral mPFC after cocaine extinction (Nic Dhonnchadha et al. 2013). In a morphine-CPP paradigm, the level of phospho-GluR1/Ser845 was found to be increased in the postsynaptic density of the hippocampus during the extinction phase (Billa et al. 2009) and also mediate mem- brane AMPA receptor trafficking (Liu et al. 2009; Lee and Kirkwood 2011). Phospho-GluR1/Ser831were found to be increased in the lateral amygdala after extinction of fear conditioning (Lee et al. 2013).

In the current study, we found membrane GluR1 increased in the VTA during METH extinction. Although phospho-GluR1/ Ser831 and Ser845 both contribute to AMPA receptor function and play a role in behavioral extinction, they seem to involve different contexts of extinction and did not display concomitant changes (Ding et al. 2013; Tao et al. 2014). Our current finding that GluR1/Ser845, but not Ser831, phosphorylation enhanced in the VTA along with an increased number of dendritic spines and AMPA insertion during METH-CPP extinction indicates this GluR1 residue-dependent neuroplasticity may involve in extinction learning at the site of VTA. Considering that mesolimbic DA activation is a hallmark for drug-dependent behavioral sensitization and appetitive cue-associated relapse or craving in human addicts (Bouton 2002), it is not surprising to find LTP-related NMDA/AMPA receptor alterations in the VTA during METH-CPP extinction. The enhanced NR1 mRNA but not protein (Supplemental Fig. S1) as well as GluR1 phosphorylation and surface expression apparently reflect an altered NMDA/AMPA signal delivered to the VTA during METH-CPP extinction. Recently, Leite-Morris et al. (2014) reported extinction of opiate reward reduces dendritic arborization as well as c-Fos expression in the NAc, implying that extinction-related, LTP-associated morphological changes might exhibit stringent tissue and drug specificity. Though there is a lack of direct evidence, we speculate that VTA GABA neurons might be targeted by glutamate projections and pass an inhibitory signal to VTA DA neurons to suppress METH-CPP during cue reexposure. In support of this notion, studies using anterograde or retrograde tracing clearly showed that pyramidal glutamate neurons in the PFC project to the VTA and form synapses with either $\mathrm{TH}^{+}$-DA somatodendrites or GABA neurons (Carr and Sesack 2000; Wedony et al. 2007). Increased membrane GluR1 also implies a change in dendritic morphology since previous studies demonstrated GluR1 redistribution in the VTA DA neurons along with altered neuroplasticity after chronic morphine or cocaine administration (Lane et al. 
A
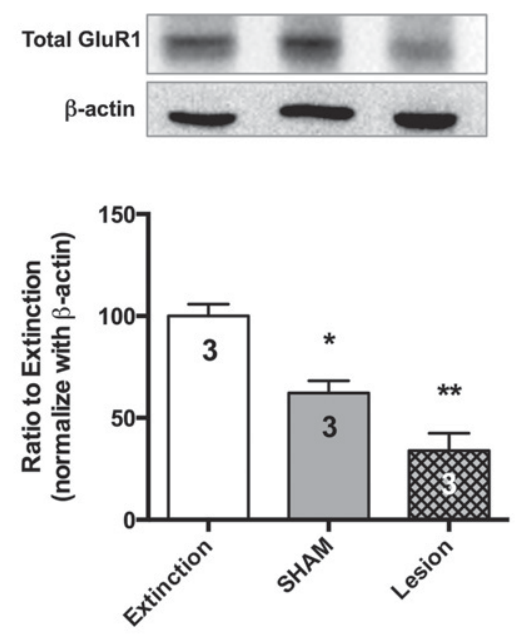

B
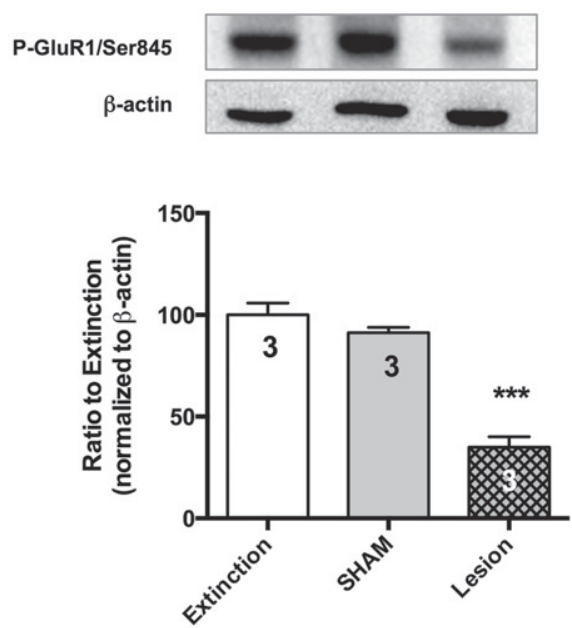

C

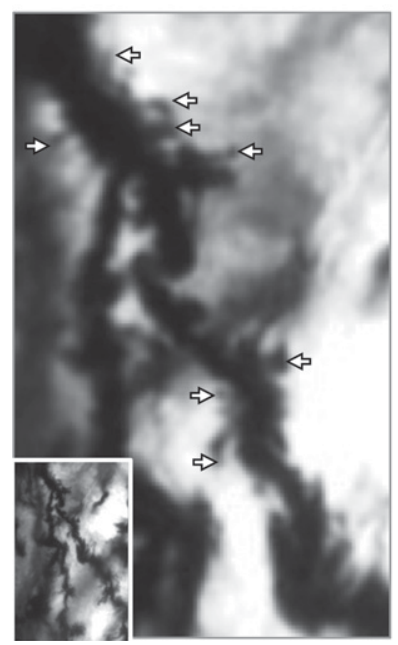

D

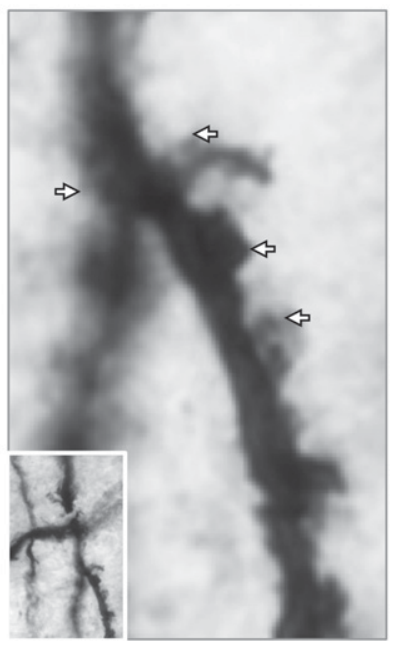

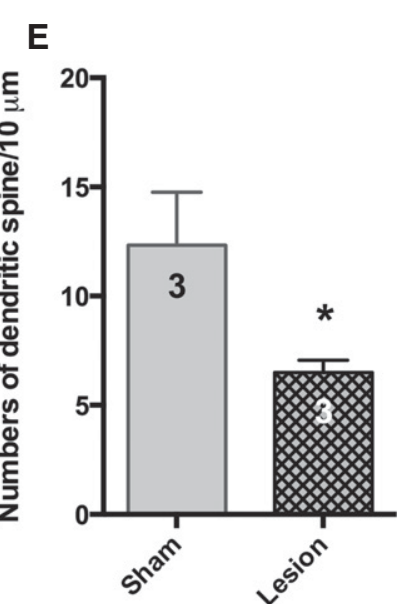

Figure 5. Effect of mPFC lesioning on protein levels of $(A)$ total GluR1, $(B)$ phosphorylated GluR1/Ser845 in the VTA during extinction of METH-CPP. Representative Western blots are shown. Bar graphs show densitometric quantification. The amount of phospho-GluR1/Ser845 or total GluR1 were normalized to $\beta$-actin with each METH-CPP extinction group set to $100 \%$. $(C, D)$ Golgi stain illustrates the structural modifications in the VTA at the stage of METH-CPP extinction with $(C)$ or without $(D)$ ibotenic acid lesion at the mPFC. (E) Bar graphs show quantification of dendritic spines. $(*) P<0.05,(* *)$ $P<0.01,\left({ }^{* *}\right) P<0.001$ compared with corresponding extinction group (Western blot) or sham controls (Golgi stain). Bilateral VTA from $\sim 2-3$ mice were pooled in each Western blot experiment and experiments were repeated three times. For Golgi stain, sections from three mice per group were calculated. Arrows indicate the dendritic spines.

2008, 2011). Whether the GluR1 trafficking occurs mainly in VTA GABA interneurons, rather than DA neurons, require further experimentation, however, it might explain the discrepancy between ours (increase during extinction) and Lane et al. 2008, 2011 (increase in acquisition).

Extensive experimental evidence indicates that inactivation of the mPFC either by lesion or pharmacological blockade impairs extinction of fear or drug conditioning (Hsu and Packard 2008; Wang et al. 2012; Gupta et al. 2013). The mPFC is known to send excitatory glutamate signals to several subcortical areas, including the amygdala, hippocampus, NAc, hypothalamus, and VTA (Frankle et al. 2006; Vazquez-Borsetti et al. 2009) to strengthen learning during extinction training. Hence, electrolytic lesioning of $\mathrm{mPFC}$, following the acquisition of ethanol-CPP, blocks the extinction of ethanol-CPP (Groblewski et al. 2012). Furthermore, local infusion of NMDA receptor antagonist bupivacaine or AP-5 into the mPFC blocked the extinction of amphetamine-CPP (Hsu and Packard 2008). Of interest, mPFC-dependent suppression of cocaine seeking could be reversed by local injection of DAMGO, an $\mu$-opioid receptor agonist, into VTA, or dopamine antagonist injection in the NAc-shell (LaLumiere et al. 2012), suggesting that both mesolimbic DA regions are functionally integrated with the MPFC in extinction-associated neural circuitry. In this context, our findings that extinction training induced membrane GluR, Ser845 phosphorylation, and that the number of dendritic spines was significantly reduced in the VTA after mPFC lesioning supports a positive role for the VTA in METH-CPP extinction. However, in an attempt to test 
if GluR1/Ser845 phosphorylation and altered dendritic spines would be reversed during stress-induced METH-CPP reinstatement, we found both parameters remained unchanged as levels of METH-CPP extinction. It is possible that this "stress"-induced drug reinstatement involves mPFC-VTA-independent neural circuitry, which reactivates the rewarding pathway at extra-VTA brain region. In support of this notion, previous study found norepinephrine, via $\beta 2$-ARs, activates CRF-releasing neurons in the BNST to evoke stress-induced cocaine reinstatement (McReynolds et al. 2014). Local injection of oxytocin into the dorsal hippocampus completely blocked the METH-CPP (Nawata et al. 2012). Another study found CRF level increased in the amygdala during foot shock-induced METH reinstatement whiles treatment of nonselective CRF inhibitor $\mathrm{CRF}_{9-41}$ attenuated METH reinstatement (Nawata et al. 2012; Han et al. 2014). Whether drug- or cue-induced METH-CPP reinstatement involves altered GluR1/Ser845 phosphorylation requires further investigation.

Consistent with an up-regulation of GluR1 phosphorylation in the VTA, we also found phospho-ERK1/2 in this brain region was recovered at extinction of METH-CPP, as compared with acquisition or withdrawal group. ERK, in particular ERK2, is known to participate in various stages of aversive or appetitive cuedependent behavioral expression or extinction (Cestari et al. 2013). Both ERK1 and ERK2 are readily phosphorylated in the NAc and dorsal striatum after acute morphine, METH, or cocaine administration (Tronson and Taylor 2007) while also evoked during morphine withdrawal or extinction in the ventral mPFC (Wang et al. 2012). Suppression of ERK and CREB phosphorylation in basolateral amygdala impairs extinction of morphine withdrawal-dependent conditioned place aversion (Wang et al. 2014). In a morphine-CPP paradigm, expression of ERK1 and ERK2 mRNA were altered with distinct patterns in various brain regions (i.e., NAc, PFC, hippocampus, and amygdala) across acquisition, extinction, and reinstatement stages (Ma et al. 2014). Of which, NAc-shell has also been considered as a core structure manipulating the extinction behavior (Chiara 2002; Xu et al. 2012). The finding of an altered ERK2 phosphorylation in the VTA across METH-CPP stages suggests this MAPK signal, along with phosphoGluR1/Ser845, would be viewed as valid biomarkers in predicting the progress of drug rewarding.

Overall, using a series of biochemical and morphological assays along with lesioning in the mPFC, we conclude that the VTA participates in extinction of appetitive cue-associated CPP. Compared with other subcortical regions, that have been identified for their involvement in extinction (i.e., amygdala, hippocampus, and NAc), the VTA seems to be unique in that it is known to initiate mesolimbic and mesocortical DA activation during drug rewarding. In the future, exploring the dual role of the VTA as an "on and off" switch in appetitive conditioning should advance our knowledge of cue-dependent drug acquisition, extinction, and reinstatement.

\section{Materials and Methods}

\begin{abstract}
Animals
Male C57BL6/J mice were aged 5-6 wk at the start of the study. Animals were group housed (five mice per cage) and maintained on a 12-h light-dark cycle (0700-1900 h). Food and water were available ad libitum in the home cages. All animal procedures were approved by the Institutional Animal Care and Use Committee of Chang-Gung University and were performed in accordance with the Guide for the Care and Use of Laboratory Animals (Institute of Laboratory Animal Resources, National Academy Press, 1996).
\end{abstract}

\section{METH-conditioned place preference (METH-CPP) paradigm}

\section{Apparatus}

CPP chambers with two equal size compartments $(15 \mathrm{~cm}$ length $\times$ $15 \mathrm{~cm}$ width $\times 20 \mathrm{~cm}$ height) separated by a transparent middle compartment $(6 \mathrm{~cm}$ length $\times 15 \mathrm{~cm}$ width $\times 20 \mathrm{~cm}$ height $)$ were used. The two large compartments were paired with two different cues (mosaic wall paper with corn bedding or white wall paper with aspen bedding) confined with two sliding doors $(6 \mathrm{~cm}$ width $\times 6 \mathrm{~cm}$ length) on each wall between middle and large compartments to allow animal to freely access their preferred arena.

\section{Acquisition}

Before the CPP test, mice were allowed to freely access two compartments for total of $600 \mathrm{sec}$ and the time spent in each compartment was recorded. During the conditioning, mice after saline injection were confined to the originally preferred compartment for $30 \mathrm{~min}$. Mice after $2 \mathrm{mg} / \mathrm{kg}$ METH injection were confined to the originally nonpreferred compartment for $30 \mathrm{~min}$ with sliding doors closed. The CPP was performed once daily with either saline or METH pairing, each for four administrations on alternative days. On day 10, each mouse was again brought to the middle compartment with both sliding doors open, and the time each mouse spent on each compartment was recorded for a total of $600 \mathrm{sec}$. The time-length spent in the drug-paired compartment before (pretest) and after the CPP conditioning is a measure of the degree of METH-CPP.

\section{Extinction}

After establishing the METH-CPP, a set of animals was subjected to a daily extinction session with a training schedule similar to the previous drug-conditioning period, except both compartments during the eight daily trainings were paired with saline. At day 19 , each mouse was again transferred to the middle compartment with sliding doors open, and the time spent in each compartment was recorded for a total of $600 \mathrm{sec}$.

\section{CPP controls}

To validate the behavioral and biochemical outcome of METHCPP, two groups of CPP control were prepared. First set of control animals (defined as saline control), after the pretest, was treated with saline and confined to CPP compartment for consecutive $8 \mathrm{~d}$ (similar to METH-CPP acquisition). After second CPP test, they were again treated with saline and confined to alternative CPP compartment for another $8 \mathrm{~d}$ (comparable with METH-CPP extinction); defined as saline control. Second set of control animals (defined as withdrawal group), after the pretest and METHCPP establishment, was subjected to a withdrawal session by housing in a new mouse cage for $30 \mathrm{~min}$ after daily saline injection and for consecutive $8 \mathrm{~d}$ (comparable with METH-CPP extinction). At day 19, each mouse was again transferred to the middle compartment with sliding door open, and the time spent in each compartment was recorded for a total of $600 \mathrm{sec}$.

\section{VTA dissection}

Mice of withdrawal control, acquisition group or extinction group were sacrificed by decapitation $\sim 15 \mathrm{~min}$ after the last corresponding METH-CPP test. The whole brain was quickly removed and immersed immediately into ice-cold KPBS solution $\left(\mathrm{KH}_{2} \mathrm{PO}_{4}\right.$ $3.3 \mathrm{mM}, \mathrm{K}_{2} \mathrm{HPO}_{4} 21.9 \mathrm{mM}, \mathrm{NaCl} 154 \mathrm{mM}$ ). Afterward, a series of $500-600 \mu \mathrm{m}$ brain slices were sectioned by a vibratome (MA752, Campden Ins.) and the VTA was isolated based on the mouse brain atlas (Paxinos and Franklin 2001) and analyzed immediately or stored in $-80^{\circ} \mathrm{C}$ freezer until analyzed. 


\section{Quantitative PCR}

Total RNAs were isolated from frozen tissues using TRIzol reagent according to the manufacturer's protocol (Thermo Fisher Scientific Inc.). The mRNA was transcribed to cDNA via reverse transcriptase (HT BioTechnology). The cDNA for corresponding targets was measured by quantitative real-time PCR using a BioRad iQ5 sequence detection instrument (Bio-Rad Laboratories, Inc.). The details for PCR condition and primer sequences are listed in Supplemental Methods.

\section{Western immunoblot}

The isolated VTA were pooled (3-4 samples per group) and lysed with heated $1 \%$ SDS solution and denatured at $100^{\circ} \mathrm{C}$ for $5 \mathrm{~min}$. Samples were sonicated, centrifuged, and the supernatants were quantified by Coomassie blue staining using bovine serum albumin as standards. Equal amount of protein samples $(\sim 20 \mu \mathrm{g})$ were separated by SDS-PAGE gels. After resolving, proteins were transferred onto a polyvinylidene difluoride (PVDF) membrane (Millipore Corporation) and then incubated for $1 \mathrm{~h}$ in a blocking buffer $(5 \%$ nonfat milk in TBS-T solution [ $20 \mathrm{mM}$ Tris base and $137 \mathrm{mM} \mathrm{NaCl}, 0.1 \%$ Tween 20, $\mathrm{pH}$ 7.6]) at room temperature, were probed with primary antibodies diluted in TBS-T buffer including $\beta$-actin, 1:1000 (Sigma-Aldrich); phospho-ERK1/2, 1:1000 (Cell Signaling); total-GluR1, 1:1000 (Santa Cruz Biotechnology, Inc.); phospho-GluR1/Ser831, 1:1000 (Cell Signaling); phospho-GluR1/Ser845, 1:1000 (Cell Signaling); $\beta$-tubulin, 1:1000 (Millipore Corporation) at $4^{\circ} \mathrm{C}$ overnight. After washing in TBS-T, the signals were probed with peroxidase-conjugated secondary antibodies (1:2000 anti-rabbit-HRP or anti-mouse-HRP in TBS-T; Sigma-Aldrich) at room temperature for another $1 \mathrm{~h}$. The labeled proteins were detected by enhanced chemiluminescence (GE Healthcare Bio-Sciences Corp.) and the signals were quantified by ChemiDoc XRS with Image Lab software (Bio-Rad Laboratories, Inc.).

\section{Synaptosomal preparations}

Mice were rapidly decapitated and the brains were transferred to an ice-cold dish. The VTA was rapidly dissected and pooled (3-4 samples per group) then immersed in 10 volumes $(\mathrm{w} / \mathrm{v})$ of ice-cold $0.32 \mathrm{M}$ sucrose. The tissues were freshly homogenized, then centrifuged at $1000 \mathrm{~g}$ for $15 \mathrm{~min}$ at $4^{\circ} \mathrm{C}$. The resulting supernatant was centrifuged at $15,000 \mathrm{~g}$ for $20 \mathrm{~min}$, and the pellets were washed by resuspending in $0.32 \mathrm{M}$ sucrose solution and defined as crude synaptosomes. The synaptosomes were then suspended in Krebs-Ringer-HEPES buffer $(120 \mathrm{mM} \mathrm{NaCl}, 4.7 \mathrm{mM} \mathrm{KCl}, 2.2$ $\mathrm{mM} \mathrm{CaCl} 2,10 \mathrm{mM}$ HEPES, $1.2 \mathrm{mM} \mathrm{MgSO}_{4}, 1.2 \mathrm{mM} \mathrm{KH}_{2} \mathrm{PO}_{4}, 5$ $\mathrm{mM}$ Tris, and $10 \mathrm{mM}$ D-glucose, $\mathrm{pH}$ 7.4). Protein concentrations were determined by Coomassie blue using bovine serum albumin as the standard.

\section{Biotinylation assay}

Freshly prepared synaptosomes $(500 \mu \mathrm{g})$ were treated with sulfoNHS-SS-biotin (1 mg/1 mg protein; Thermo Fisher Scientific Inc.) for $30 \mathrm{~min}$ at $4^{\circ} \mathrm{C}$. Subsequently, the samples were washed with radioimmunoprecipitation assay (RIPA) lysis buffer $(10 \mathrm{mM}$ Tris- $\mathrm{HCl}, 150 \mathrm{mM} \mathrm{NaCl}, 1 \mathrm{mM}$ EDTA, 1\% Triton X-100, $0.1 \%$ SDS, and $1 \%$ sodium deoxycholate, $\mathrm{pH} 7.5$ ) contained $100 \mathrm{mM}$ glycine, then the pellets were resuspended with the same buffer but supplemented with protease inhibitor cocktail $(1 \mu \mathrm{g} / \mathrm{mL}$ aprotinin, $1 \mu \mathrm{g} / \mathrm{mL}$ leupeptin, and $1 \mu \mathrm{M}$ pepstatin) and phosphatase inhibitors $(10 \mathrm{mM}$ sodium fluoride, $50 \mathrm{mM}$ sodium pyrophosphate, $5 \mathrm{mM}$ sodium orthovanadate, and $1 \mu \mathrm{M}$ okadaic acid) (Samuvel et al. 2008). The resuspended synaptosomes were then centrifuged at $40,000 \mathrm{~g}$ for $20 \mathrm{~min}$. The biotinylated proteins were separated from clear solubilizate by incubating with monomeric avidin beads (Thermo Fisher Scientific Inc.) for $3 \mathrm{~h}$ at $4^{\circ} \mathrm{C}$. Beads were washed three times with RIPA buffer, and bound biotinylated proteins were eluted with Laemmli sample buffer for $20 \mathrm{~min}$ at $22^{\circ} \mathrm{C}$. Aliquots from total extracts $(20 \mu \mathrm{g})$, unbound fractions $(20 \mu \mathrm{g})$, and entire eluted fractions were separated by
10\% SDS-PAGE, transferred to a PVDF membrane, and probed with anti-GluR1 antibody.

\section{Golgi stain}

The procedures performed using FD Rapid GolgiStain kit (FD NeuroTechnologies, Inc.) according to the manufacturer's instructions. Images were observed under a confocal laser scanning microscope (LSM 510 META NLO, Zeiss) and taken from the upmost position to the lowest side of the dendrite. Dendritic spines were calculated from $150-\mu \mathrm{m}$ thickness brain slices $(3-5$ slices in series per subject) containing VTA using nearby substantia nigra and hippocampus as landmarks, which is also identified by the coordinates. Numbers of dendritic spines were carefully quantified to avoid false identification from neiboring neurons.

\section{Surgery and intracranial microinjection}

Mice underwent brain surgery using a stereotaxic apparatus (Harvard Apparatus). Animals were anesthetized with a $5 \mathrm{~mL} / \mathrm{kg}$ mixture of $100 \mathrm{mg}$ ketamine and $50 \mathrm{mg}$ xylazine in a volume of $7.5 \mathrm{~mL}$. Brains were lesioned with ibotenic acid $(5 \mu \mathrm{g} / 3 \mu \mathrm{L})$ in the top surface of infralimbic cortex. The coordinates for lesion were: $0.18 \mathrm{~cm}$ anterior to bregma, $\pm 0.02 \mathrm{~cm}$ lateral toward the midline, and $0.25 \mathrm{~cm}$ ventral to the skull surface. Considering the ibotenic acid solution could infuse into infralimbic cortex but also, via back flow, infiltrate into upper prelimbic cortex, the chemical damage thus would be viewed as an mPFC lesion. Each mouse was given a $4 \mathrm{mg} / \mathrm{kg}$ ampicillin injection after the surgery and watched closely for any abnormal behaviors during recovery period. Mice that received lesions or sham operation were rested for $48 \mathrm{~h}$ prior to the METH-CPP test.

\section{Statistics}

Data were analyzed with the program GraphPad Prism and were expressed as mean \pm SEM. Two-way ANOVA was used to analyze overall significance among different CPP stages under distinct experimental paradigm. Repeated-measures one-way ANOVA was used to analyze the differences in CPP scores. Nonparametric oneway ANOVA was used to analyze numbers of dendritic spine or quantitative Western blot results among the testing groups. The post hoc comparisons were made using Tukey's test for biochemical analysis and Bonferroni test for behavioral measurements. A P value of $<0.05$ was considered to be significant.

\section{Acknowledgments}

We thank Dr Marcus Calkins for English editing. This work was supported by the National Science Council (NSC101-2320B-182-040-MY3), Chang Gung Memorial Hospital (CMRPD 180522), and CGU Healthy Ageing Research Center (EMRPD 1B0311), Taiwan.

\section{References}

Aguilar MA, Rodriguez-Arias M, Miñarro J. 2009. Neurobiological mechanisms of the reinstatement of drug-conditioned place preference. Brain Res Rev 59: 253-277.

Akirav I, Maroun M. 2007. The role of the medial prefrontal cortex-amygdala circuit in stress effects on the extinction of fear. Neural Plast 2007: 30873.

Ball KT, Slane M. 2012. Differential involvement of prelimbic and infralimbic medial prefrontal cortex in discrete cue-induced reinstatement of 3,4-methylenedioxymethamphetamine (MDMA; ecstasy) seeking in rats. Psychopharmacology 224: 377-385.

Billa SK, Sinha N, Rudrabhatla SR, Morón JA. 2009. Extinction of morphine-dependent conditioned behavior is associated with increased phosphorylation of the GluR1 subunit of AMPA receptors at hippocampal synapses. Eur J Neurosci 29: 55-64.

Bouton ME. 2002. Context, ambiguity, and unlearning: sources of relapse after behavioral extinction. Biol Psychiatry 52: 976-986.

Carr DB, Sesack SR. 2000. Projections from the rat prefrontal cortex to the ventral tegmental area: target specificity in the synaptic associations 
with mesoaccumbens and mesocortical neurons. J Neurosci 20: $3864-3873$

Cestari V, Rossi-Arnaud C, Saraulli D, Costanzi M. 2013. The MAP(K) of fear: from memory consolidation to memory extinction. Brain Res Bull 105: 8-16.

Chiara GD. 2002. Nucleus accumbens shell and core dopamine: differential role in behavior and addiction. Behav Brain Res 137: 75-114.

Cleva RM, Gass JT, Widholm JJ, Olive MF. 2010. Glutamatergic targets for enhancing extinction learning in drug addiction. Curr Neuropharmacol 8: $394-408$.

Conklin C, Tiffany S. 2002. Applying extinction research and theory to cueexposure addiction treatments. Addiction 97: 155-167.

Crespo JA, Oliva JM, Ghasemzadeh MB, Kalivas PW, Ambrosio E. 2002. Neuroadaptive changes in NMDAR1 gene expression after extinction of cocaine selfadministration. Ann N Y Acad Sci 965: 78-91.

Crombag HS, Shaham Y. 2002. Renewal of drug seeking by contextual cues after prolonged extinction in rats. Behav Neurosci 116: 169-173.

Derkach VA, Oh MC, Guire ES, Soderling TR. 2007. Regulatory mechanisms of AMPA receptors in synaptic plasticity. Nat Rev Neurosci 8: 101-113.

Ding X, Liang J, Zheng X, Bai Y, Liu Z, Li Y, Xing X. 2013. Altered phosphorylation of GluA1 in the striatum is associated with locomotor sensitization induced by exposure to increasing doses of morphine. Eur J Pharmacol 702: 294-301.

Fortin DA, Davare MA, Srivastava T, Brady JD, Nygaard S, Derkach VA, Soderling TR. 2010. Long-term potentiation-dependent spine enlargement requires synaptic $\mathrm{Ca}^{2+}$-permeable AMPA receptors recruited by CaM-kinase I. J Neurosci 30: 11565-11575.

Frankle WG, Laruelle M, Haber SN. 2006. Prefrontal cortical projections to the midbrain in primates: evidence for a sparse connection. Neuropsychopharmacology 31: 1627-1636.

Ghasemzadeh MB, Mueller C, Vasudevan P. 2009a. Behavioral sensitization to cocaine is associated with increased glutamate receptor trafficking to the postsynaptic density after extended withdrawal period. Neuroscience 159: $414-426$.

Ghasemzadeh MB, Vasudevan P, Mueller C, Seubert C, Mantsch JR. 2009b. Region specific alterations in glutamate receptor expression and subcellular distribution following extinction of cocaine self-administration. Brain Res 1267: 89-102.

Girault JA, Valjent E, Caboche J, Hervé D. 2007. ERK2: a logical AND gate critical for drug-induced plasticity? Curr Opin Pharmacol 7: 77-85.

Grillon C. 2008. Models and mechanisms of anxiety: evidence from startle studies. Psychopharmacology (Berl) 199: 421-437.

Groblewski PA, Ryabinin AE, Cunningham CL. 2012. Activation and role of the medial prefrontal cortex (mPFC) in extinction of ethanol-induced associative learning in mice. Neurobiol Learn Mem 97: 37-46.

Guedea AL, Schrick C, Guzman YF, Leaderbrand K, Jovasevic V, Corcoran KA, Tronson NC, Radulovic J. 2011. ERK-associated changes of AP-1 proteins during fear extinction. Mol Cell Neurosci 47: 137-144.

Gupta SC, Hillman BG, Prakash A, Ugale RR, Stairs DJ, Dravid SM. 2013. Effect of D-cycloserine in conjunction with fear extinction training on extracellular signal-regulated kinase activation in the medial prefrontal cortex and amygdala in rat. Eur J Neurosci 37: 1811-1822.

Haaker J, Lonsdorf TB, Thanellou A, Kalisch R. 2013. Multimodal assessment of long-term memory recall and reinstatement in a combined cue and context fear conditioning and extinction paradigm in humans. PLoS One 8: e76179.

Han WY, Du P, Fu SY, Wang F, Song M, Wu CF, Yang JY. 2014. Oxytocin via its receptor affects restraint stress-induced methamphetamine CPP reinstatement in mice: involvement of the medial prefrontal cortex and dorsal hippocampus glutamatergic system. Pharmacol Biochem Behav 119: $80-87$.

Henley JM, Wilkinson KA. 2013. AMPA receptor trafficking and the mechanisms underlying synaptic plasticity and cognitive aging. Dialogues Clin Neurosci 15: 11-27.

Hsu E, Packard MG. 2008. Medial prefrontal cortex infusions of bupivacaine or AP-5 block extinction of amphetamine conditioned place preference. Neurobiol Learn Mem 89: 504-512.

Indovina I, Robbins TW, Núñez-Elizalde AO, Dunn BD, Bishop SJ. 2011. Fear-conditioning mechanisms associated with trait vulnerability to anxiety in humans. Neuron 69: 563-571.

Jenkins MA, Traynelis SF. 2012. PKC phosphorylates GluA1-Ser831 to enhance AMPA receptor conductance. Channels 6: 60-64.

Kalivas PW, Volkow ND. 2011. New medications for drug addiction hiding in glutamatergic neuroplasticity. Mol Psychiatry 16: 974-986.

Kelamangalath L, Swant J, Stramiello M, Wagner JJ. 2007. The effects of extinction training in reducing the reinstatement of drug-seeking behavior: involvement of NMDA receptors. Behav Brain Res 185: $119-128$.

Kessels HW, Malinow R. 2009. Synaptic AMPA receptor plasticity and behavior. Neuron 61: 340-350.

Knackstedt LA, Moussawi K, Lalumiere R, Schwendt M, Klugmann M, Kalivas PW. 2010. Extinction training after cocaine self-administration induces glutamatergic plasticity to inhibit cocaine seeking. J Neurosci 30: $7984-7992$.

Kreek MJ, LaForge KS, Butelman E. 2002. Pharmacotherapy of addictions. Nat Rev Drug Discov 1: 710-726.

LaLumiere RT, Smith KC, Kalivas PW. 2012. Neural circuit competition in cocaine-seeking: roles of the infralimbic cortex and nucleus accumbens shell. Eur I Neurosci 35: 614-622.

Lane DA, Lessard AA, Chan J, Colago EE, Zhou Y, Schlussman SD, Kreek MJ, Pickel VM. 2008. Region-specific changes in the subcellular distribution of AMPA receptor GluR1 subunits in the rat ventral tegmental area following acute or chronic morphine administration. J Neurosci 28: 9670-9681.

Lane DA, Reed B, Kreek MJ, Pickel VM. 2011. Differential glutamate AMPA-receptor plasticity in subpopulations of VTA neurons in the presence or absence of residual cocaine: Implications for the development of addiction. Neuropharmacology 61: 1129-1140.

Lee HK, Kirkwood A. 2011. AMPA receptor regulation during synaptic plasticity in hippocampus and neocortex. Semin Cell Dev Biol 22: 514-520.

Lee S, Song B, Kim J, Park K, Hong I, An B, Song S, Lee J, Park S, Kim J, et al. 2013. GluA1 phosphorylation at serine 831 in the lateral amygdala is required for fear renewal. Nat Neurosci 16: 1436-1444.

Leite-Morris KA, Kobrin KL, Guy MD, Young AJ, Heinrichs SC, Kaplan GB. 2014. Extinction of opiate reward reduces dendritic arborization and c-Fos expression in the nucleus accumbens core. Behav Brain Res 263: 51-59.

Liu Y, Sun QA, Chen Q, Lee TH, Huang Y, Wetsel WC, Michelotti GA, Sullenger BA, Zhang X. 2009. Targeting inhibition of GluR1 Ser845 phosphorylation with an RNA aptamer that blocks AMPA receptor trafficking. J Neurochem 108: 147-157.

Lüscher C, Malenka RC. 2011. Drug-evoked synaptic plasticity in addiction: from molecular changes to circuit remodeling. Neuron 69: $650-663$

Ma JY, Gu SZ, Meng M, Dang YH, Huang CY, Onaivi ES. 2014. Regional expression of extracellular signal-regulated kinase 1 and 2 mRNA in a morphine-induced conditioned place preference model. Brain Res 1543: $191-199$.

Mao SC, Hsiao YH, Gean PW. 2006. Extinction training in conjunction with a partial agonist of the glycine site on the NMDA receptor erases memory trace. J Neurosci 26: 8892-8899.

McReynolds JR, Vranjkovic O, Thao M, Baker DA, Makky K, Lim Y, Mantsch JR. 2014. $\beta-2$ adrenergic receptors mediate stress-evoked reinstatement of cocaine-induced conditioned place preference and increases in CRF mRNA in the bed nucleus of the stria terminalis in mice. Psychopharmacology (Berl) 231: 3953-3963.

Millan EZ, McNally GP. 2012. Cocaine- and amphetamine-regulated transcript in the nucleus accumbens shell attenuates context-induced reinstatement of alcohol seeking. Behav Neurosci 126: 690-698.

Nawata Y, Kitaichi K, Yamamoto T. 2012. Increases of CRF in the amygdala are responsible for reinstatement of methamphetamine-seeking behavior induced by footshock. Pharmacol Biochem Behav 101: 297-302.

Nic Dhonnchadha BA, Lin A, Leite-Morris KA, Kaplan GB, Man HY, Kantak KM. 2013. Alterations in expression and phosphorylation of GluA1 receptors following cocaine-cue extinction learning. Behav Brain Res 238: 119-123.

Paxinos G, Franklin KBJ. 2001. The mouse brain in stereotaxic coordinates, 2nd ed. Academic, NY.

Peters J, LaLumiere RT, Kalivas PW. 2008. Infralimbic prefrontal cortex is responsible for inhibiting cocaine seeking in extinguished rats. J Neurosci 28: 6046-6053.

Peters J, Kalivas PW, Quirk GJ. 2009. Extinction circuits for fear and addiction overlap in prefrontal cortex. Learn Mem 16: 279-288.

Quirk GJ, Mueller D. 2008. Neural mechanisms of extinction learning and retrieval. Neuropsychopharmacology 33: 56-72.

Samuvel DJ, Jayanthi LD, Manohar S, Kaliyaperumal K, See RE, Ramamoorthy S. 2008. Dysregulation of dopamine transporter trafficking and function after abstinence from cocaine self-administration in rats: evidence for differential regulation in caudate putamen and nucleus accumbens. J Pharmacol Exp Ther 325: $293-301$.

Spaethling J, Le L, Meaney DF. 2012. NMDA receptor mediated phosphorylation of GluR1 subunits contributes to the appearance of calcium-permeable AMPA receptors after mechanical stretch injury. Neurobiol Dis 46: 646-654.

Sutton MA, Schmidt EF, Choi KH, Schad CA, Whisler K, Simmons D, Karanian DA, Monteggia LM, Neve RL, Self DW. 2003. Extinction-induced upregulation in AMPA receptors reduces cocaine-seeking behaviour. Nature 421: 70-75.

Tao W, Chen Q, Zhou W, Wang Y, Wang L, Zhang Z. 2014. Persistent inflammation-induced upregulation of BDNF promotes synaptic delivery of $\alpha$-amino-3-hydroxy-5-methyl-4-isoxazole-propionic acid 
receptor GluA1 subunits in descending pain modulatory circuits. J Biol Chem 289: 22196-22204.

Taylor JR, Olausson P, Quinn JJ, Torregrossa MM. 2009. Targeting extinction and reconsolidation mechanisms to combat the impact of drug cues on addiction. Neuropharmacology 56: 186-195.

Tronson NC, Taylor JR. 2007. Molecular mechanisms of memory reconsolidation. Nat Rev Neurosci 8: 262-275.

Tzschentke TM. 2001. Pharmacology and behavioral pharmacology of the mesocortical dopamine system. Prog Neurobiol 63: 241-320.

Vazquez-Borsetti P, Cortes R, Artigas F. 2009. Pyramidal neurons in rat prefrontal cortex projecting to ventral tegmental area and dorsal raphe nucleus express 5-HT2A receptors. Cereb Cortex 19: 1678-1686.

Wang WS, Kang S, Liu WT, Li M, Liu Y, Yu C, Chen J, Chi ZQ, He L, Liu JG. 2012. Extinction of aversive memories associated with morphine withdrawal requires ERK-mediated epigenetic regulation of brain-derived neurotrophic factor transcription in the rat ventromedial prefrontal cortex. J Neurosci 32: 13763-13775.

Wang WS, Chen ZG, Liu WT, Chi ZQ, He L, Liu JG. 2014. Dorsal hippocampal NMDA receptor blockade impairs extinction of naloxone-precipitated conditioned place aversion in acute morphine-treated rats by suppressing ERK and CREB phosphorylation in the basolateral amygdala. Br J Pharmacol 172: 482-491.

Wedony K, Chocyk A, Kolasiewicz W, Maćkowiak M. 2007. Glutamatergic neurons of rat medical prefrontal cortex innervating the ventral tegmental area are positive for serotonin 5-HT1A receptor protein. J Physiol Pharmacol 58: 611-624.

Willcocks AL, McNally GP. 2013. The role of medial prefrontal cortex in extinction and reinstatement of alcohol-seeking in rats. Eur J Neurosci 37: $259-268$

Xu Y, Lv XF, Cui CL, Ge FF, Li YJ, Zhang HL. 2012. Essential role of NR2B-containing NMDA receptor-ERK pathway in nucleus accumbens shell in morphine-associated contextual memory. Brain Res Bull 89: 22-30.

Yap JJ, Miczek KA. 2008. Stress and rodent models of drug addiction: role of VTA-accumbens-PFC-amygdala circuit. Drug Discov Today Dis Models 5: $259-270$.

Yetnikoff L, Reichard RA, Schwartz ZM, Parsely KP, Zahm DS. 2014. Protracted maturation of forebrain afferent connections of the ventral tegmental area in the rat. J Comp Neurol 522: 1031-1047.

Zavala AR, Biswas S, Harlan RE, Neisewander JL. 2007. Fos and glutamate AMPA receptor subunit coexpression associated with cue-elicited cocaine-seeking behavior in abstinent rats. Neuroscience 145: 438-452.

Received December 3, 2014; accepted in revised form December 22, 2014. 


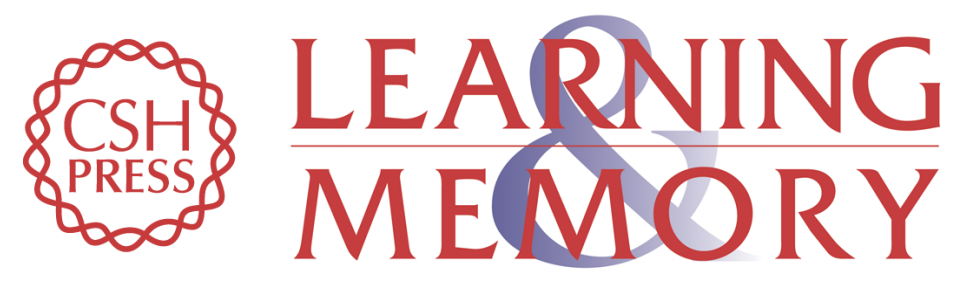

\section{Role of the ventral tegmental area in methamphetamine extinction: AMPA receptor-mediated neuroplasticity}

Han-Ting Chen and Jin-Chung Chen

Learn. Mem. 2015, 22:

Access the most recent version at doi:10.1101/Im.037721.114

\section{Supplemental http://learnmem.cshlp.org/content/suppl/2015/02/12/22.3.149.DC1 Material}

References This article cites 67 articles, 10 of which can be accessed free at: http://learnmem.cshlp.org/content/22/3/149.full.html\#ref-list-1

Creative This article is distributed exclusively by Cold Spring Harbor Laboratory Press for the Commons first 12 months after the full-issue publication date (see

License http://learnmem.cshlp.org/site/misc/terms.xhtml). After 12 months, it is available under a Creative Commons License (Attribution-NonCommercial 4.0 International), as described at http://creativecommons.org/licenses/by-nc/4.0/.

Email Alerting Receive free email alerts when new articles cite this article - sign up in the box at the Service top right corner of the article or click here. 